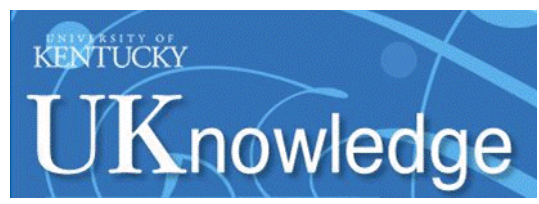

University of Kentucky

UKnowledge

3-22-2018

\title{
Selective Laser Melting of Ni-Rich NiTi: Selection of Process Parameters and the Superelastic Response
}

Narges Shayesteh Moghaddam

The University of Toledo

Soheil Saedi

University of Kentucky, soheil.saedi@uky.edu

Amirhesam Amerinatanzi

University of Kentucky

Ehsan Saghaian

University of Kentucky

Ahmadreza Jahadakbar

The University of Toledo

See next page for additional authors

Follow this and additional works at: https://uknowledge.uky.edu/me_facpub

Part of the Materials Science and Engineering Commons, and the Mechanical Engineering Commons Right click to open a feedback form in a new tab to let us know how this document benefits you.

\section{Repository Citation}

Moghaddam, Narges Shayesteh; Saedi, Soheil; Amerinatanzi, Amirhesam; Saghaian, Ehsan; Jahadakbar, Ahmadreza; Karaca, Haluk E.; and Elahinia, Mohammad, "Selective Laser Melting of Ni-Rich NiTi: Selection of Process Parameters and the Superelastic Response" (2018). Mechanical Engineering Faculty Publications. 52.

https://uknowledge.uky.edu/me_facpub/52

This Conference Proceeding is brought to you for free and open access by the Mechanical Engineering at UKnowledge. It has been accepted for inclusion in Mechanical Engineering Faculty Publications by an authorized administrator of UKnowledge. For more information, please contact UKnowledge@lsv.uky.edu. 


\title{
Selective Laser Melting of Ni-Rich NiTi: Selection of Process Parameters and the Superelastic Response
}

\author{
Digital Object Identifier (DOI) \\ https://doi.org/10.1117/12.2305247
}

\section{Notes/Citation Information}

Published in Proceedings of SPIE, v. 10596, Behavior and Mechanics of Multifunctional Materials and Composites XII, article 105960W, p. 1-7.

(C) 2018 SPIE. One print or electronic copy may be made for personal use only. Systematic reproduction and distribution, duplication of any material in this paper for a fee or for commercial purposes, or modification of the content of the paper are prohibited.

Narges Shayesteh Moghaddam, Soheil Saedi, Amirhesam Amerinatanzi, Ehsan Saghaian, Ahmadreza Jahadakbar, Haluk Karaca, and Mohammad Elahinia, "Selective laser melting of Ni-rich NiTi: selection of process parameters and the superelastic response," Proc. SPIE 10596, Behavior and Mechanics of Multifunctional Materials and Composites XII, 105960W (March 22, 2018). DOI: https://doi.org/10.1117/ 12.2305247

The copyright holder has granted the permission for posting the article here.

\section{Authors}

Narges Shayesteh Moghaddam, Soheil Saedi, Amirhesam Amerinatanzi, Ehsan Saghaian, Ahmadreza Jahadakbar, Haluk E. Karaca, and Mohammad Elahinia 


\section{Selective laser melting of Ni-rich NiTi: selection of process parameters and the superelastic response}

Narges Shayesteh Moghaddam, Soheil Saedi, Amirhesam Amerinatanzi, Ehsan Saghaian, Ahmadreza Jahadakbar, et al.

Narges Shayesteh Moghaddam, Soheil Saedi, Amirhesam Amerinatanzi, Ehsan Saghaian, Ahmadreza Jahadakbar, Haluk Karaca, Mohammad Elahinia, "Selective laser melting of Ni-rich NiTi: selection of process parameters and the superelastic response," Proc. SPIE 10596, Behavior and Mechanics of Multifunctional Materials and Composites XII, 105960W (22 March 2018); doi: 10.1117/12.2305247

Event: SPIE Smart Structures and Materials + Nondestructive Evaluation and Health Monitoring, 2018, Denver, Colorado, United States 


\title{
Selective laser melting of Ni-rich NiTi: Selection of process parameters and the superelastic response
}

\author{
Narges Shayesteh Moghaddam ${ }^{\mathrm{a}}$, Soheil Saedi ${ }^{\mathrm{b}}$, Amirhesam Amerinatanzi ${ }^{\mathrm{b}}$, Ehsan Saghaian ${ }^{\mathrm{b}}$, \\ Ahmadreza Jahadakbar ${ }^{\text {a }}$, Haluk Karaca ${ }^{\mathrm{b}}$, Mohammad Elahinia ${ }^{\mathrm{a}}$ \\ ${ }^{a}$ Dynamic and Smart Systems Laboratory, Mechanical Industrial and Manufacturing Engineering \\ Department, The University of Toledo, OH 43606, USA; \\ ${ }^{\mathrm{b}}$ Department of Mechanical Engineering, University of Kentucky, Lexington, KY 40506-0503, USA
}

\begin{abstract}
Material and mechanical properties of NiTi shape memory alloys strongly depend on the fabrication process parameters and the resulting microstructure. In selective laser melting, the combination of parameters such as laser power, scanning speed, and hatch spacing determine the microstructural defects, grain size and texture. Therefore, processing parameters can be adjusted to tailor the microstructure and mechanical response of the alloy. In this work, NiTi samples were fabricated using $\mathrm{Ni}_{50.8} \mathrm{Ti}$ (at.\%) powder via SLM PXM by Phenix/3D Systems and the effects of processing parameters were systematically studied. The relationship between the processing parameters and superelastic properties were investigated thoroughly. It will be shown that energy density is not the only parameter that governs the material response. It will be shown that hatch spacing is the dominant factor to tailor the superelastic response. It will be revealed that with the selection of right process parameters, perfect superelasticity with recoverable strains of up to $5.6 \%$ can be observed in the as-fabricated condition.
\end{abstract}

Keywords: Shape memory alloys, Ni-rich NiTi, Superelasticity, Additive manufacturing, Selective laser melting, Biomedical implants.

\section{INTRODUCTION}

In recent years, shape memory alloys (SMAs) have attracted much attention in various fields such as automotive [1, 2], biomedicine [3, 4], and aerospace [5, 6]. NiTi alloys as the most common SMA demonstrate unique functional properties, i.e., superelasticity and shape memory properties. These functional properties cause the NiTi components to recover large strains up to 8\% upon unloading and unloading-heating-cooling, respectively [7-9]. In addition, NiTi alloys demonstrate other desirable characteristics such as low modulus of elasticity ( $\sim 47 \mathrm{GPa})[10,11]$, adequate fatigue life $\left(2 \mathrm{~N}_{\mathrm{f}}=1271\right.$ at $\left.\varepsilon_{\max }=3.0 \%\right)[12,13]$, biocompatibility, corrosion resistant (corrosion rate $<0.89$ mpy), and high damping ratio $(0.038 \pm$ 0.004 in austenite; $0.002 \pm 0.004$ in martensite) [14-16].

In spite of the great interest in NiTi alloys, it is a very challenging task to fabricate them using conventional techniques because of the associated high reactivity and high deformability of these alloys [17, 18]. To name a few, conventional techniques include arc or induction melting, followed by a hot working process and eventually machining to the final shape. Thanks to additive manufacturing (AM) techniques, the fabrication of complex NiTi geometries, such as porous structures, component with hole, or curved samples have been recently realized. The AM techniques for fabrication of NiTi alloys are either powder-bed based (e.g., Selective Laser Melting (SLM)) or flow-based (e.g., Laser Engineered Net Shaping (LENS)). In powder-bed based AM techniques, a roller, blade, or knife deposit a powder layer on top of the building substrate while the powder is provided through one or more nozzles in flow-based AM techniques [19]. SLM is the most common AM technique for fabrication of complex NiTi parts [7, 8].

In SLM technique, the CAD model of the part and the supports are first sliced into subsequent layers with predefined thicknesses typically ranging from 20 to $100 \mu \mathrm{m}$. Each layer contains the SLM processing parameters (e.g., laser power$\mathrm{P}$, hatch spacing-h, scanning speed-v, layer thickness-t, scanning strategy). Next, a powder layer is deposited on top of the building plate with the thickness similar to that of sliced CAD layer. Then, the high-power laser selectively melts the powder layer according to the geometrical information of the corresponding sliced CAD. Once solidified, the building plate goes down by the thickness of a powder layer to allow the deposition of the next powder layer. The procedure is

Behavior and Mechanics of Multifunctional Materials and Composites XII, edited by Hani E. Naguib, Proc. of SPIE Vol. 10596, 105960W - @ 2018 SPIE CCC code: $0277-786 X / 18 / \$ 18 \cdot$ doi: $10.1117 / 12.2305247$ 
repeated until the production of the CAD file is completed. Finally, the surrounding powder and supports are removed to obtain the final geometry. Figure 1 summarizes the steps during the SLM fabrication.

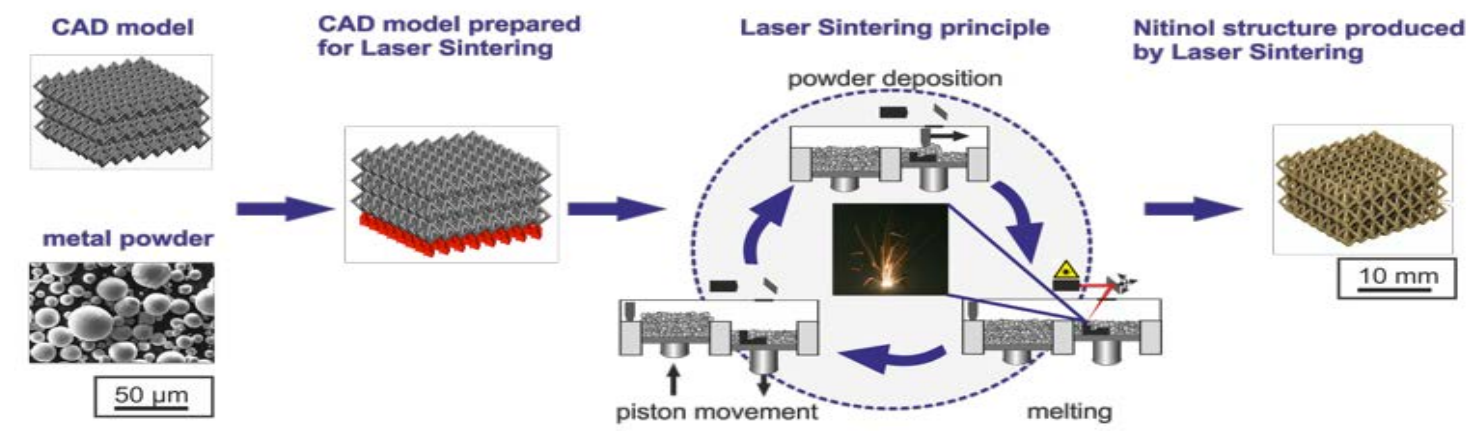

Figure 1. The schematic of SLM fabrication [19].

In biomedical applications, the superelasticity feature of NiTi alloys is an essential factor as it allows the implants to behave similar to bone through recovering a large amount of deformation (up to $8 \%$ strain). It has been reported in the literature that both SLM processing parameters and post heat treatments affect the superelasticity properties of SLM NiTi. Haberland et al. [20] reported stabilized superelasticity with strain recovery of $3.4 \%$ and the recovery ratio $\left(\varepsilon_{r e c} / \varepsilon_{\text {tot }}\right)$ of $95 \%$ in SLM $\mathrm{Ni}_{50.7} \mathrm{Ti}$ (at. \%) after solution annealing and subsequent aging at $350^{\circ} \mathrm{C}$ for $24 \mathrm{~h}$. Saedi et al. [21] reported higher strain recovery of $5.5 \%$ and recovery ratio $\left(\varepsilon_{r e c} / \varepsilon_{t o t}\right)$ of $95 \%$ in the solution annealed Ni-rich $\mathrm{Ni}_{50.8} \mathrm{Ti}$ (at. \%) sample aged at $350^{\circ} \mathrm{C}$ for $18 \mathrm{~h}$. Later, Saedi et al. [18] demonstrated that high energy input (E=P/(v.h.t)) of $222 \mathrm{~J} / \mathrm{mm}^{3}$ through low P and low $\mathrm{v}$ result in superelasticity. They observed strain recovery of $5.77 \%$ in the first cycle in the sample. There is no work in literature focusing on the effect of $h$ on the superelastic response of SLM NiTi structures.

The focus of this research was to evaluate the influence of $h$ on the superelastic response of SLM Ni ${ }_{50.8} \mathrm{Ti}$ (at.\%). To this aim, the processing parameters of $\mathrm{P}, \mathrm{v}$, and t were considered to be $250 \mathrm{~W}, 1250 \mathrm{~mm} / \mathrm{s}$, and $30 \mu \mathrm{m}$ while h was altered from 80 to $180 \mu \mathrm{m}$. In this work, microstructure, transformation temperatures (TTs), and the superelastic behavior of all the samples were studied.

\section{MATERIALS AND METHODS}

\subsection{Fabrication}

The $\mathrm{Ni}_{50.8} \mathrm{Ti}$ (at. \%) ingots were purchased from Nitinol Devices \& Components, Inc. (Fremont, CA). The ingots were atomized to powder by TLS Technik GmbH (Bitterfeld Germany) using an electrode induction-melting gas atomization (EIGA) technique. A range of 25-75 $\mu \mathrm{m}$ powder particle fraction was used as this fraction resulted in appropriate flowability, density, and impurity [22]. A Phenix PXM by 3D Systems (Rock Hill, SC) was used to fabricated cylindrical samples with $4.5 \mathrm{~mm}$ diameter and $10 \mathrm{~mm}$ length for compression testing. Table 1 indicates the processing parameters implemented for the fabrication of the samples. Alternating x-y scanning strategy was also implemented [19]. 
Table 1. The implemented SLM processing parameters for fabrication of Ni-rich NiTi structures.

\begin{tabular}{cccccc}
\hline Sample \# & $\begin{array}{c}\text { Laser power- } \\
(\mathbf{W a t t})\end{array}$ & $\begin{array}{c}\text { Scanning speed- } \\
\mathbf{v}(\mathbf{m m} / \mathbf{s})\end{array}$ & $\begin{array}{c}\text { Layer thickness- } \\
\mathbf{t}(\boldsymbol{\mu m})\end{array}$ & $\begin{array}{c}\text { Hatch spacing-h } \\
(\boldsymbol{\mu m})\end{array}$ & $\begin{array}{c}\text { Energy input-E } \\
\left(\mathbf{J} / \mathbf{m m}^{\mathbf{3}}\right)\end{array}$ \\
\hline $\mathbf{1}$ & 250 & 1250 & 30 & 80 & 83.3 \\
\hline $\mathbf{2}$ & 250 & 1250 & 30 & 100 & 66.7 \\
\hline $\mathbf{3}$ & 250 & 1250 & 30 & 120 & 55.6 \\
\hline $\mathbf{4}$ & 250 & 1250 & 30 & 140 & 47.6 \\
\hline $\mathbf{5}$ & 250 & 1250 & 30 & 160 & 41.7 \\
\hline $\mathbf{6}$ & 250 & 1250 & 30 & 180 & 37.0 \\
\hline
\end{tabular}

\subsection{Experimental Procedure}

TTs was determined using a Perkin-Elmer DSC Pyris 1 with the heating/cooling rate of $10^{\circ} \mathrm{C} / \mathrm{min}$ in nitrogen atmosphere. Superelastic response was evaluated through thermo-mechanical tests using $100 \mathrm{kN}$ MTS Landmark servo-hydraulic test platform. A strain rate of $10^{-4} \mathrm{~s}^{-1}$ was employed during loading while unloading was conducted under force control at a rate of $100 \mathrm{~N} / \mathrm{s}$. The strain was measured by a mechanical MTS high- temperature extensometer attached to the grips.

\section{RESULTS}

\subsection{Microstructural Properties}

Figure 2 (a) and (b) show the optical images of two SLM NiTi samples processed with extremely low $\mathrm{h}(\mathrm{h}=80 \mu \mathrm{m})$ and high $\mathrm{h}(\mathrm{h}=180 \mu \mathrm{m})$, respectively. It is clear that $\mathrm{h}=80$ sample only contains micro voids as the melting tracks are overlapping each other. On the other hand, porosities and imperfections increase with higher h spacing.
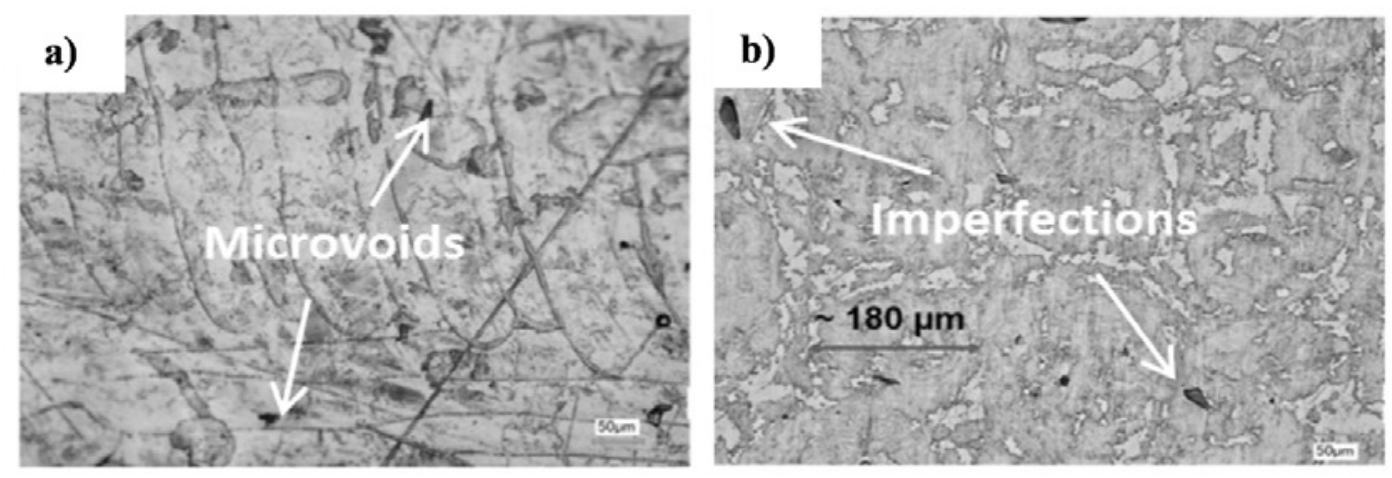

Figure 2. Optical micrographs of SLM Ni50.8Ti (at.\%) samples fabricated by (a) h=80 $\mu \mathrm{m}$ and (b) h=180 $\mu \mathrm{m}$.

\subsection{Phase Transformation Response}

Figure 3 (a) and (b) show the variation of TTs ( $A_{f}$-Blue line, $M_{s}$-Red line) as a function of $h$ and $E$, respectively. It is clear that TTs increase as the amount of $\mathrm{E}$ increase (lower $\mathrm{h}$ ). This can be explained by the fact that higher implemented $\mathrm{E}$ causes the melt pools to be held at a high temperature for a longer periods of time, which, in turn, result in the higher rate of Nickel (i.e., Ni) evaporation. It has been reported that such Ni depletion is associated with an increase in TTs [23, 24]. 
a)

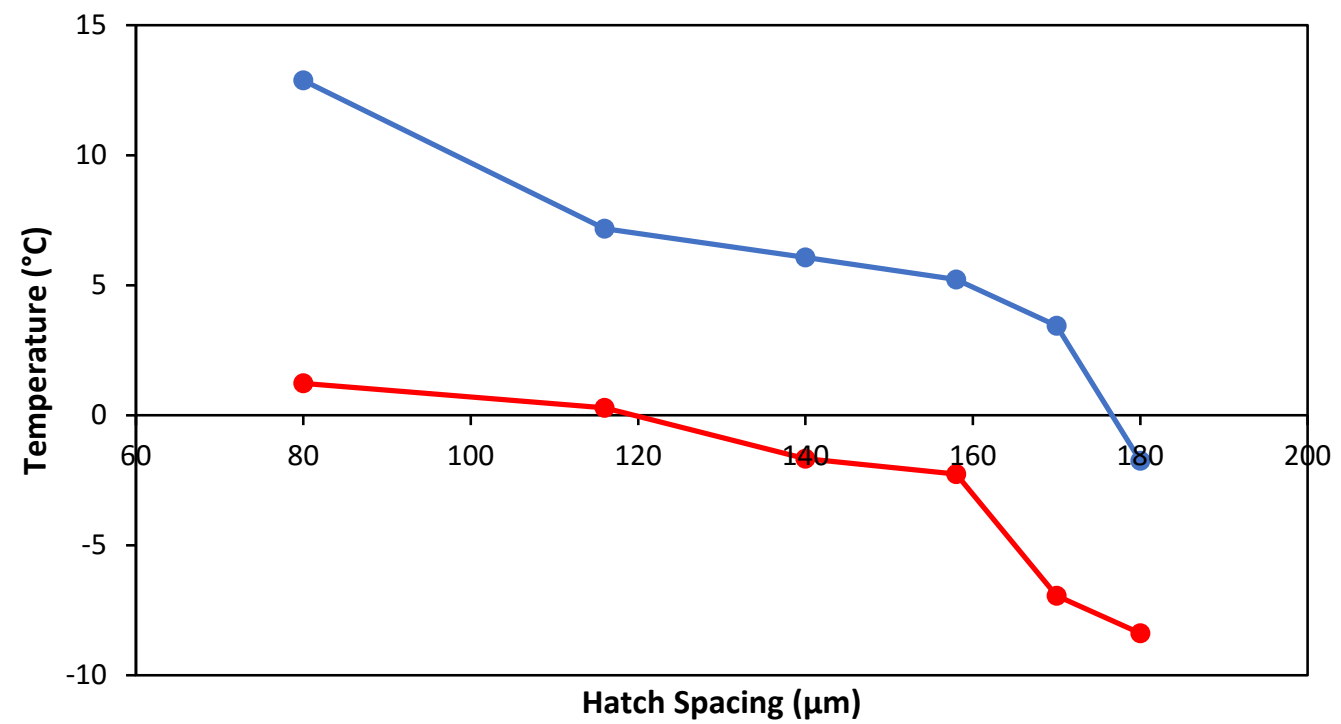

b)

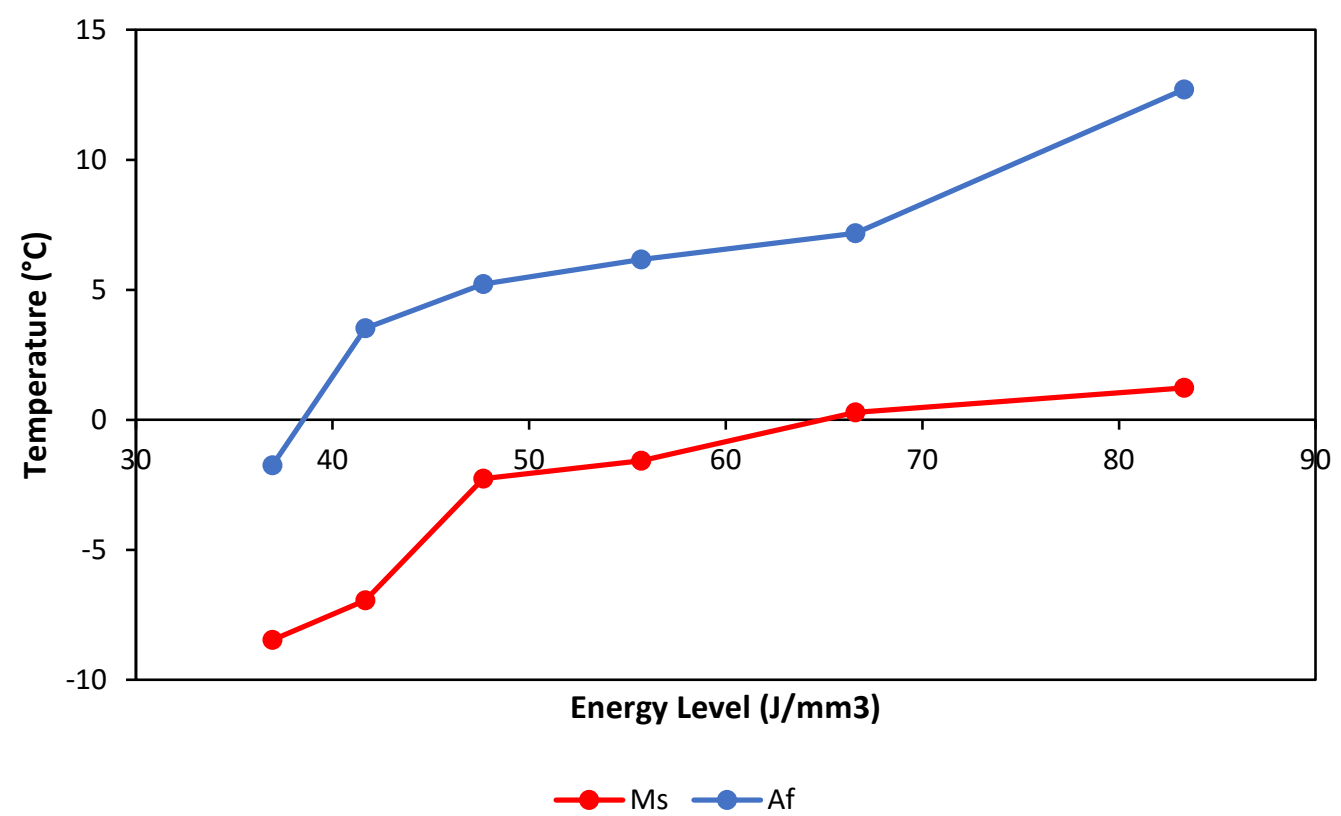

Figure 3. Transformation temperatures of SLM Nis0.8 $\mathrm{Ti}$ (at.\%) as function of (a) hatch spacing-h and (b) Energy level-E.

\subsection{Superelastic response}

Figure 4 demonstrates the superelastic responses of SLM Ni50.8 $\mathrm{Ti}$ (at.\%) samples tested at a temperature above $\mathrm{A}_{\mathrm{f}}$. The stress-strain plots indicate that lower values for h (higher E) result in the best superelastic response. For a better clarification, the total strain $\left(\varepsilon_{\text {tot }}\right)$, irrecoverable strain $\left(\varepsilon_{\text {Irrec }}\right)$, and recoverable strain $\left(\varepsilon_{\text {rec }}\right)$ of the samples are also demonstrated in Table 2. For example, the sample processed by $h=80$ demonstrates high $\varepsilon_{\text {rec }}$ of 5.62 and negligible amount of $\varepsilon_{\text {Irrec }}$. 


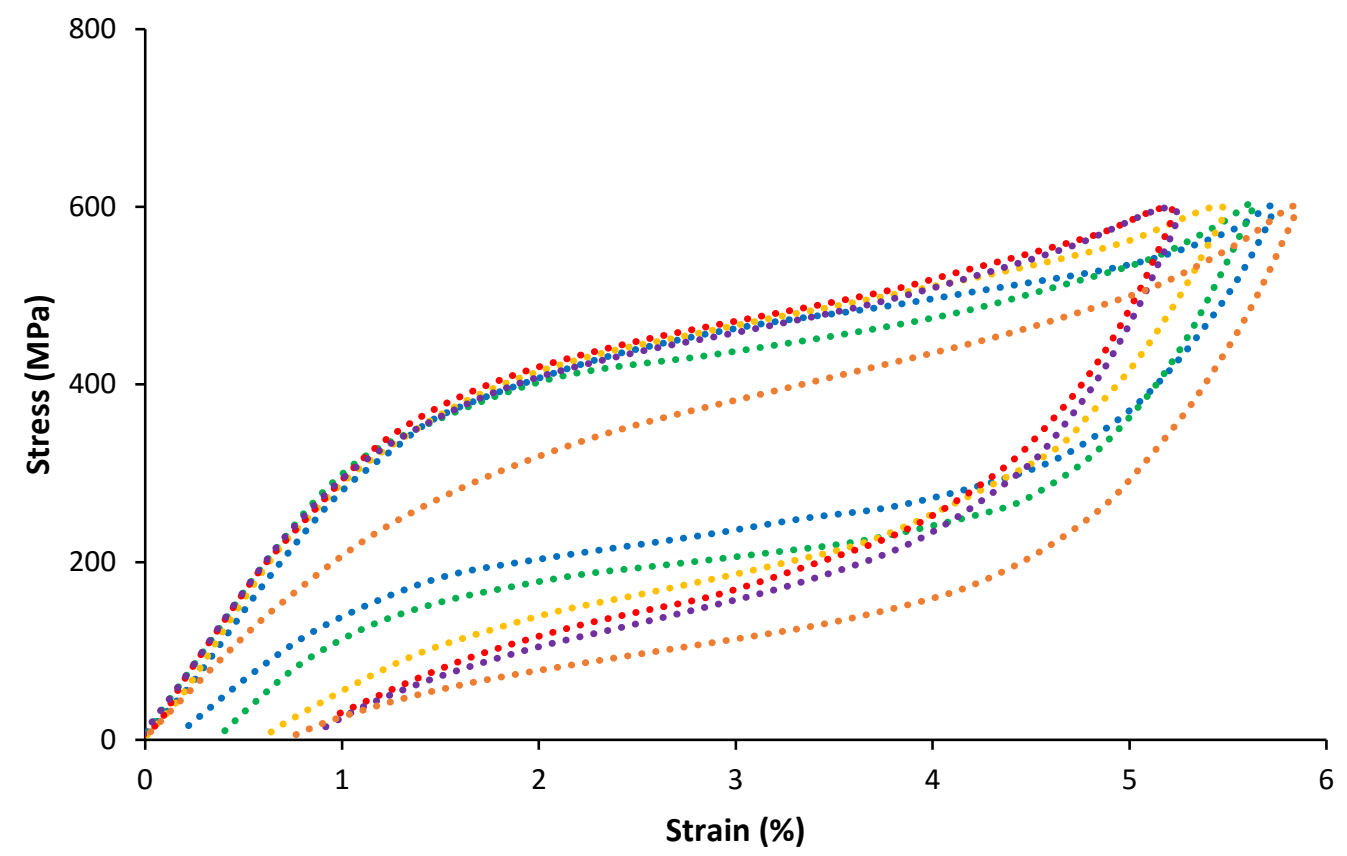

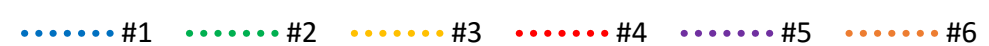

Figure 4. The superelastic response of samples tested at room.

Table 2 . The total strain $\left(\varepsilon_{\text {tot }}\right)$, irrecoverable strain $\left(\varepsilon_{\text {Irrec }}\right)$, and recoverable strain $\left(\varepsilon_{\text {rec }}\right)$ of SLM NiTi samples processed with different values of $\mathrm{h}$.

\begin{tabular}{cccc}
\hline Sample \# & $\boldsymbol{\varepsilon}_{\text {tot }}(\mathbf{\%})$ & $\boldsymbol{\varepsilon}_{\text {Irrec }}(\mathbf{\%})$ & $\boldsymbol{\varepsilon}_{\text {rec }}(\mathbf{\%})$ \\
\hline $\mathbf{1}$ & 5.72 & 0.10 & 5.62 \\
\hline $\mathbf{3}$ & 5.51 & 0.38 & 5.13 \\
\hline $\mathbf{4}$ & 5.47 & 0.62 & 4.85 \\
\hline $\mathbf{5}$ & 5.12 & 0.8 & 4.32 \\
\hline $\mathbf{6}$ & 5.22 & 0.87 & 4.35 \\
\hline
\end{tabular}

\section{SUMMARY AND CONCLUSION}

In this study, we evaluated the influence of h on the microstructure, TTs, and superelastic response of SLM Ni-rich NiTi. To this aim, several cylindrical samples were fabricated using $\mathrm{Ni}_{50.8} \mathrm{Ti}$ (at. \%) powder via SLM PXM by Phenix/3D Systems. The samples were then analyzed through DSC analysis and compression loading-unloading testing. The main findings of the study are outlined as follow:

- TTs were increased as h was decreased. This was attributed to the corresponding higher level of Ni evaporation. 
- The samples processed with lower $\mathrm{h}$ resulted in better superelastic response. For example, h=80 sample demonstrated strain recovery of 5.62\% with negligible irrecoverable strain.

The findings of this research suggest that h factor significantly affect the final properties of the SLM NiTi samples. Further investigations are however required to find the main reason behind such observations, which may help to further optimize the processing parameters.

\section{ACKNOWLEDGEMENTS}

The authors would like to acknowledge the financial support provided for the project "Nitinol Commercialization Accelerator" and TVSF awards.

\section{REFERENCES}

[1] A. Pelton, V. Schroeder, M. Mitchell et al., "Fatigue and durability of Nitinol stents," Journal of the mechanical behavior of biomedical materials, 1(2), 153-164 (2008).

[2] Y. Z. Mehran, M. Nafari, A. Nafari et al., "Histogram shifting as a data hiding technique: An overview of recent developments." 770-786.

[3] S. Robertson, and R. Ritchie, “A fracture-mechanics-based approach to fracture control in biomedical devices manufactured from superelastic Nitinol tube,” Journal of Biomedical Materials Research Part B: Applied Biomaterials, 84(1), 26-33 (2008).

[4] C. Ma, M. T. Andani, H. Qin et al., "Improving surface finish and wear resistance of additive manufactured nickel-titanium by ultrasonic nano-crystal surface modification,” Journal of Materials Processing Technology, 249, 433-440 (2017).

[5] M. Elahinia, N. S. Moghaddam, A. Amerinatanzi et al., “Additive manufacturing of NiTiHf high temperature shape memory alloy,” Scripta Materialia, 145, 90-94 (2018).

[6] A. Sedaghat, I. Samani, M. Ahmadi-Baloutaki et al., "Computational study on novel circulating aerofoils for use in Magnus wind turbine blades,” Energy, 91, 393-403 (2015).

[7] N. S. Moghaddam, A. Amerinatanzi, S. Saedi et al., "Stiffness Tuning of NiTi Implants Through Aging." V001T02A014-V001T02A014.

[8] D. Stoeckel, “Nitinol medical devices and implants,” Minimally invasive therapy \& allied technologies, 9(2), 8188 (2000).

[9] M. Mahtabi, N. Shamsaei, and M. Mitchell, "Fatigue of Nitinol: The state-of-the-art and ongoing challenges," journal of the mechanical behavior of biomedical materials, 50, 228-254 (2015).

[10] N. S. Moghaddam, M. T. Andani, A. Amerinatanzi et al., "Metals for bone implants: safety, design, and efficacy,” Biomanufacturing Reviews, 1(1), 1 (2016).

[11] A. Amerinatanzi, H. Zamanian, N. Shayesteh Moghaddam et al., “Application of the Superelastic NiTi Spring in Ankle Foot Orthosis (AFO) to Create Normal Ankle Joint Behavior,” Bioengineering, 4(4), 95 (2017).

[12] A. Bagheri, M. J. Mahtabi, and N. Shamsaei, "Fatigue behavior and cyclic deformation of additive manufactured NiTi,” Journal of Materials Processing Technology, 252, 440-453 (2018).

[13] H. Lavvafi, M. E. Lewandowski, D. Schwam et al., "Effects of surface laser treatments on microstructure, tension, and fatigue behavior of AISI 316LVM biomedical wires,” Materials Science and Engineering: A, 688, 101-113 (2017).

[14] M. de Wild, F. Meier, T. Bormann et al., "Damping of selective-laser-melted NiTi for medical implants,” Journal of materials engineering and performance, 23(7), 2614-2619 (2014).

[15] N. Shayesteh Moghaddam, A. Jahadakbar, A. Amerinatanzi et al., "Fixation Release and the Bone Bandaid: A New Bone Fixation Device Paradigm,” Bioengineering, 4(1), 5 (2017).

[16] M. Mehrpouya, H. Lavvafi, and A. Darafsheh, [Microstructural Characterization and Mechanical Reliability of Laser-Machined Structures] Elsevier, (2018).

[17] M. H. Wu, "Fabrication of nitinol materials and components." 394, 285-292.

[18] S. Saedi, N. S. Moghaddam, A. Amerinatanzi et al., "On the effects of selective laser melting process parameters on microstructure and thermomechanical response of Ni-rich NiTi,” Acta Materialia, 144, 552-560 (2018). 
[19] N. S. Moghaddam, A. Jahadakbar, A. Amerinatanzi et al., "Recent Advances in Laser-Based Additive Manufacturing," Laser-Based Additive Manufacturing of Metal Parts: Modeling, Optimization, and Control of Mechanical Properties, (2017).

[20] C. Haberland, H. Meier, and J. Frenzel, "On the properties of Ni-rich NiTi shape memory parts produced by selective laser melting." 97-104.

[21] S. Saedi, A. S. Turabi, M. T. Andani et al., "The influence of heat treatment on the thermomechanical response of Ni-rich NiTi alloys manufactured by selective laser melting,” Journal of Alloys and Compounds, 677, 204-210 (2016).

[22] D. Gu, W. Meiners, K. Wissenbach et al., "Laser additive manufacturing of metallic components: materials, processes and mechanisms," International materials reviews, 57(3), 133-164 (2012).

[23] M. Elahinia, N. S. Moghaddam, M. T. Andani et al., "Fabrication of NiTi through additive manufacturing: a review,” Progress in Materials Science, 83, 630-663 (2016).

[24] S. Shiva, I. Palani, S. Mishra et al., "Investigations on the influence of composition in the development of Ni-Ti shape memory alloy using laser based additive manufacturing,” Optics \& Laser Technology, 69, 44-51 (2015). 